\title{
Arteriyel Sertlik Parametrelerinin Ultrasonografi ile Ölçümünde Ölçücülerin Uyumu
}

\author{
Agreement of the Raters in Ultrasonographic Measurement of the Arterial Stiffness Param- \\ eters
}

Murat BAYKARA ${ }^{1}$, Halit VİCDAN ${ }^{1}$, İhsan YAVUZATMACA², Özcan EMRE

${ }^{1}$ Kahramanmaraş Sütçü İmam Üniversitesi Tip Fakültesi, Radyoloji Anabilim Dalı, KAHRAMANMARAŞ

${ }^{2}$ Kilis Devlet Hastanesi Radyoloji Kliniği, KİLİS

${ }^{3}$ Göksun Devlet Hastanesi Radyoloji Kliniği, KAHRAMANMARAŞ

\section{Özet}

Amaç: Özelliklerin ölçülmesinde, standart bir ölçme aracı olabilme ve sonrasında uygun bilgiler üretme yeteneğine sahiplik; ölçüm değerlerinin tutarlılığının bir göstergesi olan "güvenilirlik" ve ölçmenin amaçladığı özelliği doğru ölçebilme derecesinin göstergesi olan "geçerlilik" özelliklerine sahip olmadır. Ateroskleroz varlığı ve yaygınlığının noninvaziv olarak belirlenmesine yönelik kullanılan birçok yöntemden biri olan intima medya kalınlığı (İMK) ile arteryel sertlik (stiffness) ölçümleri en yaygın kullanılanlarındandır.

Gereç ve Yöntem: Yüksek çözünürlüklü bir Doppler ultrasonografi sistemi ile gönüllülerde ultrasonografik damar ölçümleri yapıldı. Farklı ölçücülerin ölçüm uyumu Cronbach's Alpha katsayısı hesaplanarak değerlendirildi.

Bulgular: Çap ölçümlerinde düşük değerler de alabilmesine rağmen ölçülen parametre sayısı arttıkça katsayının artışı ve sonuçta yüksek değerler göstererek 'iyi' ve 'mükemmel' sonuçlar doğurdu.

Sonuç: Bu çalışmanın bulguları, farklı ölçücüler tarafından sağlanan sonuçların özellikle ortalama değerler kullanıldığında artan güvenilirliğinin ve ölçücüler arasındaki uyumun istatistikî göstergesidir.

Anahtar Kelimeler: Ultrasonografi, vasküler sertlik, sonuçların tekrarlanabilirliği
Abstract

Objective: Concerning the measurement of the properties, be able a standard measuring tool and followed by hosting the ability to produce appropriate information must have these properties; "reliability" which is an indicator of the consistency of the measured values and "validity" which is an indicator of the accuracy of measurement degree. Intima-media thickness (IMT) and arterial stiffness measurements are the most commonly used method for determining the presence and prevalence of atherosclerosis.

Materials and Methods: In volunteers, vascular measurements were performed with using a high resolution doppler ultrasound system. Measuring compatibility of the different raters was assessed by calculating the Cronbach's alpha coefficient.

Results: Although there are low values for diameter measurement, following the increase in the number of parameters measured we were obtained that higher values, coefficient increases and 'good' and 'excellent' results.

Conclusion: The findings of this study, especially when used average values the results provided by the different raters showed statistically high realibility and high compatibility.

Key Words: Music, Physiology, Brain, Epilepsy, Therapy.

\section{GİRIS}

Yaşam süresince pek çok biyolojik strese maruz kalan vasküler yapılarda 'arteriyel sertlik' meydana gelmektedir. Arteriyel sertlik, arterlerin duvar yapısının elastik özelliğinin azalmasıdır. Yaşlanma, hipertansiyon, ateroskleroz, diabetes mellitus ve romatoid artrit gibi çok sayıda kardiyovasküler ve temelde kardiyovasküler olmayan hastalıkta arteriyel sertlik artış1 saptanmıştır. Arteriyel sertlik artışının bağımsız olarak tek başına mortalite ve morbidite habercisi olduğu da gösterilmiştir. Artmış arteriyel sertlik özellikle büyük arterlerin tamponlama yeteneğini bozarak kardiyak performans ve organ perfüzyonu üzerinde olumsuz etkiler oluşturmaktadır. Arteriyel sertlikte artmaya bağlı olarak sistolik basınç ve nabız basıncı artarken diyastolik kan basıncı azalır ve santral ve periferik arterler arasındaki elastik gradyent ortadan kalkar. Santral arterlerdeki artmış basıncin periferik arterlere yansıması sonucu organ ve dokulardaki mikrovasküler yapılar üzerinde olumsuz etkiler ortaya çıkmaktadır (1-7).

Ölçmenin istatistiksel tarifi 'ilgilenilen özelliğe sahiplik derecesinin, belirli kurallar ile semboller, özellikle de sayılar kullanarak istatistiksel birimlerle eşleştirilmesidir (8). Bir özellik ancak ölçülebilinir ve sayısal olarak ifade edilebilinirse elde olunan bu veriler aracılığıyla bilimsel araştırmalar yapılabilir, bilimsel olarak değerlendirilebilir ve açıklanabilir. Nicelik ve ölçülebilir nitelik bakımından değişiklik gösteren bir gözlem olan "değişken verileri" standart ölçme teknikleri ile saptanan sayısal değerlerden oluşmalıdır. Bu değerleri ölçmede kullanılacak olan ölçme aracının (ölçek, ölçer) standart bir ölçme aracı olması verilerin istatistiksel özelliklerde olmasını sağlar (9).

\section{Bu çalışma 36. Ulusal Radyoloji Kongresinde sözlü bildiri olarak sunulmuştur.}

$\begin{array}{ll}\text { İletişim: } & \begin{array}{l}\text { Dr. Halit Vicdan, Kahramanmaraş Sütçü İmam Üniver- } \\ \text { sitesi Tıp Fakültesi Radyoloji Anabilim Dalı, Kahraman- } \\ \text { maraş }\end{array} \\ \text { DOI: } & \mathbf{1 0 . 1 7 5 1 7 / k s u t f d . 3 0 2 5 4 0}\end{array}$

$\begin{array}{ll}\text { Tel } \quad & 05052511542 \\ \text { E-Posta } \quad: & \text { halitvicdan@hotmail.com } \\ \text { Geliş Tarihi : } & 30.11 .2016 \\ \text { Kabul Tarihi : } & 13.01 .2017\end{array}$




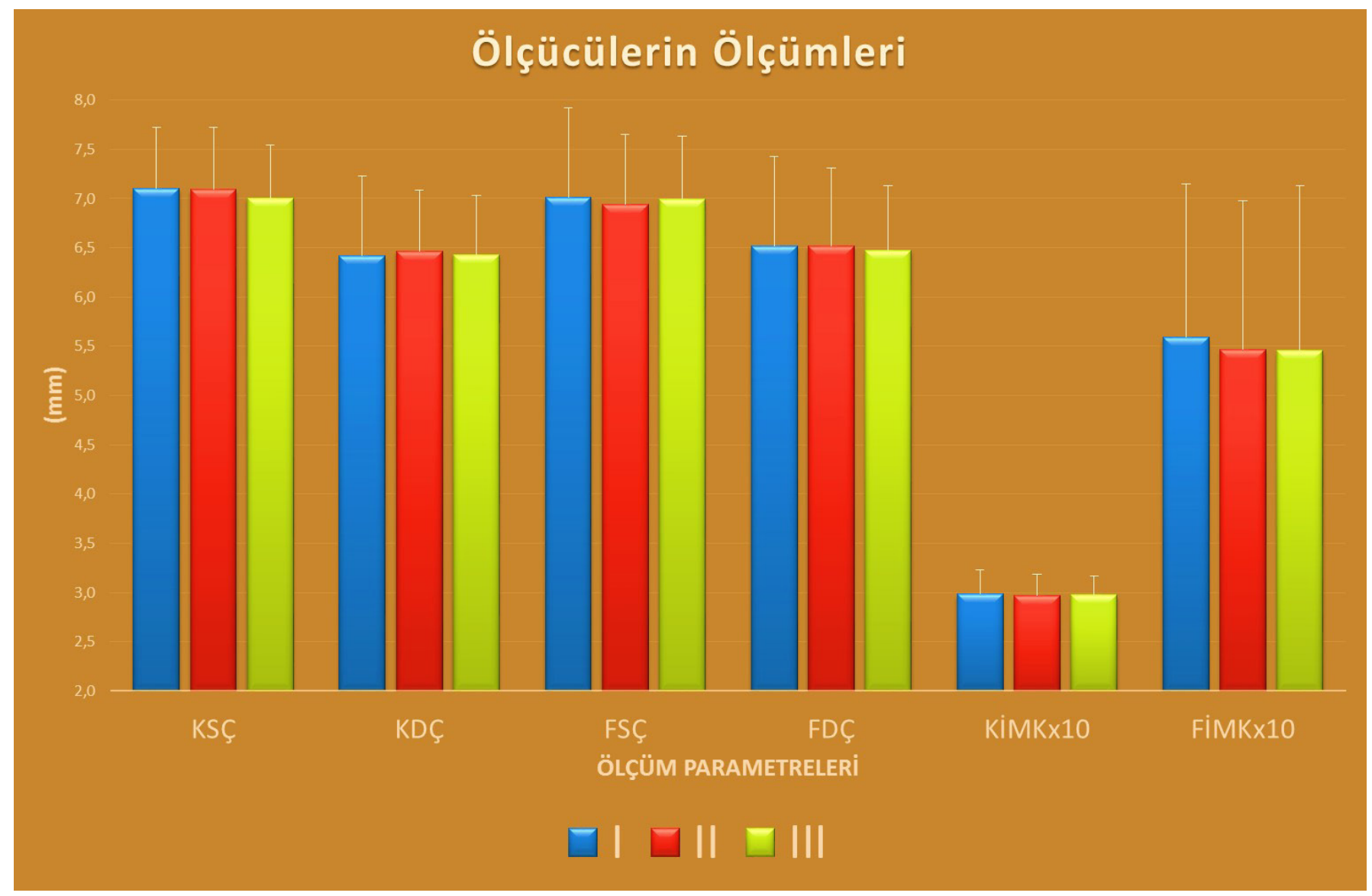

Tablo 1. 'Cronbach's Alpha'katsayısının her bir ölçüm parametresinde ve parametreler birlikte değerlendirildiğinde aldiğı değerler.

\begin{tabular}{|l|c|}
\hline \multicolumn{1}{|c|}{ Ölçüm } & Cronbach's Alpha \\
\hline Karotis Sistolik Çap & 0,815 \\
\hline Karotis Diyastolik Çap & 0,856 \\
\hline Femoral Sistolik Çap & 0,885 \\
\hline Femoral Diyastolik Çap & 0,880 \\
\hline Karotis Çaplar & 0,877 \\
\hline Femoral Çaplar & 0,894 \\
\hline Karotis + Femoral Çaplar & 0,887 \\
\hline Karotis İntima Medya Kalınlığı & 0,904 \\
\hline Femoral İntima Medya Kalınlığ & 0,970 \\
\hline Karotis + Femoral İntima Medya & 0,987 \\
\hline Kalınlığ & 0,996 \\
\hline Çaplar + İntima Medya Kalınlığı & \\
\hline
\end{tabular}

Ateroskleroz varllı̆g 1 ve yaygınlığının noninvaziv olarak belirlenmesine yönelik birçok yöntem geliştirilmiştir ve intima medya kalınlığı (IMK) ile arteriyel sertlik (stiffness) ölçümleri bu yöntemlerin en yaygın kullanılanlarındandır $(10,11)$. Kanın sol ventrikülden çıkan aorta atılması aortu dilate eder ve arteriyel ağaca belli hızlarda yayılım gösteren bir nabız dalgası oluşturur. $\mathrm{Bu}$ dalganın yayılım hızı arteriyel sertliğin bir ölçütü olan nabız dalga hızıdır. Hız ne kadar yüksekse arteriyel sertlik o kadar fazla ve arteriyel genişleyebilme kabiliyeti (distensibilite) o kadar zayıftır.
Arteriyel mekanik strese neden olan faktör basınçtır. $\mathrm{Bu}$ basıncin neden olduğu çap değişikliği ise "strain" olarak adlandırılır. Bu iki fizyolojik olay arasındaki ilişki arteriyel elastisite ve sertliği yansitır. Elastisite ve sertliğin kantitatif karşıllkları ise uyum (kompliyans) ve genişleyebilirlik (distensibilite)'dir. Distensibilite, basınç artışına göre çaptaki oransal değişimi, kompliyans ise basınç artışına göre çaptaki mutlak değişimi ifade eder. Sertlik, uyum ve genişleyebilirlik kavramlarına zıt anlamda bir kavramdır. Elastisite ise genişleyebilirliğin kantitatif ölçümüdür $(2,12)$.

$\mathrm{Bu}$ çalışmada ölçücüler arasında farklılık olup olmadığını belirlemek amaçlandı.

\section{GEREÇ VE YÖNTEM}

\section{Etik Kurul ve Çalışma Grubu}

Kahramanmaraş Sütçü İmam Üniversitesi Tip Fakültesi Bilimsel Araştırmalar Etik Kurul'unun 12.01.2015 tarihli 224 protokol, 06 karar no'lu onay1 alındıktan sonra, yaşları 18-55 arasında değişen ve onamları alınan sağlıklı gönüllülerle çalışıldı.

\section{Uygulama}

Gönüllülerin cinsiyet ve yaş değerleri kaydedildikten sonra literatürde (12) tariflenmiş olan arteriyel sertlik değerleri olan; intima medya kalınlığ (IMK), lümen diyastolik çapı (DÇ) ve lümen sistolik çap1 (SÇ) için ölçümler yapıldı. 
Tablo 2. Grup içi uyum katsayısının her bir ölçüm parametresinde ve parametreler birlikte değerlendirildiğinde aldığ değerler.

\begin{tabular}{|c|c|c|c|c|}
\hline \multicolumn{5}{|c|}{ Grup İçi Uyum Katsayısı } \\
\hline \multirow{2}{*}{\multicolumn{2}{|c|}{ Ölçüm }} & \multirow{3}{*}{$\begin{array}{c}\text { Grup İçiUyum } \\
\text { Alt Sınır } \\
0,612\end{array}$} & \multicolumn{2}{|c|}{ \%95 Güven Aralığ1 } \\
\hline & & & Alt Sinir & \\
\hline \multirow{2}{*}{ Karotis Sistolik Çap } & Tek & & 0,275 & 0,853 \\
\hline & Ortalama & 0,826 & 0,532 & 0,946 \\
\hline \multirow{2}{*}{ Karotis Diyastolik Çap } & Tek & 0,682 & 0,370 & 0,884 \\
\hline & Ortalama & 0,866 & 0,638 & 0,958 \\
\hline \multirow{2}{*}{ Femoral Sistolik Çap } & Tek & 0,734 & 0,452 & 0,906 \\
\hline & Ortalama & 0,892 & 0,712 & 0,967 \\
\hline \multirow{2}{*}{ Femoral Diyastolik Çap } & Tek & 0,727 & 0,438 & 0,903 \\
\hline & Ortalama & 0,889 & 0,701 & 0,965 \\
\hline \multirow{2}{*}{ Karotis Çaplar } & Tek & 0,711 & 0,520 & 0,851 \\
\hline & Ortalama & 0,881 & 0,765 & 0,945 \\
\hline \multirow{2}{*}{ Femoral Çaplar } & Tek & 0,746 & 0,569 & 0,870 \\
\hline & Ortalama & 0,898 & 0,798 & 0,953 \\
\hline \multirow{2}{*}{ Karotis + Femoral Çaplar } & Tek & 0,727 & 0,603 & 0,825 \\
\hline & Ortalama & 0,889 & 0,820 & 0,934 \\
\hline \multirow{2}{*}{ Karotis İntima Medya Kalınlığı } & Tek & 0,773 & 0,515 & 0,921 \\
\hline & Ortalama & 0,911 & 0,761 & 0,972 \\
\hline \multirow{2}{*}{ Femoral İntima Medya Kalınlığı } & Tek & 0,921 & 0,809 & 0,974 \\
\hline & Ortalama & 0,972 & 0,927 & 0,991 \\
\hline \multirow{2}{*}{$\begin{array}{l}\text { Karotis + Femora lİntima Medya } \\
\text { Kalınlığ }\end{array}$} & Tek & 0,962 & 0,927 & 0,982 \\
\hline & Ortalama & 0,987 & 0,975 & 0,994 \\
\hline \multirow{2}{*}{ Çaplar + İntima Medya Kalınlığı } & Tek & 0,989 & 0,984 & 0,993 \\
\hline & Ortalama & 0,996 & 0,994 & 0,998 \\
\hline
\end{tabular}

Ölçümler üç ayrı ölçümcü tarafından her bir gönüllü için ayrı ayrı ve birbirlerinden habersiz olarak yüksek çözünürlüklü Doppler ultrasonografi sistemi (Aplio $^{\mathrm{TM}} 400$ Platinum, Toshiba Medical Systems Corporation, Tochigi, Japan) ve geniş bandlı lineer prob (PLT-704AT) kullanılarak yapıldı. Damarların İMK, DÇ ve SÇ değerleri; prob sağda karotis arter bifurkasyon öncesine ve femoral arterde sağda derin dalın ayrıldığ yerin $2 \mathrm{~cm}$ distaline yerleştirilerek ölçüldü.

\section{İstatistiksel Değerlendirme}

Veriler ortalama + standart sapma $(\mathrm{O}+\mathrm{SS})$ ile ifade edildi. İstatistik için IBM SPSS for Windows, version 22.0 (IBM statistics for Windows version 22, IBM Corparation, Armonk, New York, United States) programı kullanıld1.

Ölçücüler arasındaki uyumu belirlemek için SPSS programında 'Analyze/Scale/Reliability Analysis';'Model: $\quad$ Alpha';'Statistics','Intraclass Correlation Coefficient', 'Model: Two-way mixed', 'Type: Absolute Agreement' ve 'Confidence Interval: 95\%' seçenekleri ile ölçüm değerleri test edilerek 'grup içi uyum katsayısı' (Cronbach's Alpha) bulundu.

\section{BULGULAR}

Gönüllülerin 8'i erkek 4'ü kadın olmak üzere sayısı toplam 12 idi. Ortalama yas $35,33 \pm 11,06$ y1l olup medyan yaş 37,5 y1l olarak bulundu. Hesaplanan grup içi uyum katsayıları, her bir ölçüm parametresinde ve parametreler birlikte değerlendirildiğinde aldığı değerlerle Resim 1, Tablo 1 ve 2'de gösterilmektedir.

\section{TARTIŞMA}

Ölçme, Türk Dil Kurumu (TDK) Güncel Türkçe Sözlük'e göre "ölçmek işi”, TDK Eğitim Terimleri Sözlüğü 1974'e göre "bir ya da daha çok kişiye ilişkin bir değişken niteliğin niceliğini ya da derecesini saptama ve sayısal olarak belirtme işı” "ve TDK Yöntembilim Terimleri Sözlüğü 1981'e göre İngilizce "measurement" karşıllı̆ı olarak bir ölçme araciyla nesneler ve özellikler arasında nitel ve nicel ayrımlar yapma olarak tariflenmektedir (13).

Ölçüm, TDK Güncel Türkçe Sözlük'e göre "ölçme işi; ölçülerek elde edilen sonuç; ölçümleme sonucu, takdir", TDK Fizik Terimleri Sözlügü 1983’e göre İngilizce 'measurement' karşıllı̆ı olarak "en, boy, oylum, süre gibi nicelikleri kendi cinslerinden seçilmiş bir birimle karşılaştırıp kaç birim geldiğini belirtme ișlemi”, TDK Kimya Terimleri Sözlüğü 1981'e göre İngilizce 'measurement' karşıllı̆̆ 1 olarak "özdeğin türlü görünümlerini ve bunların niteliklerini karşılaştırabilmek ve dolayisıyla niceliklerini belirleyebilmek amaciyla nesnelere, ilişkin olduğu niteliğe uygun belli kurallara 
Tablo 3. Güvenilirlik ve geçerlilik değerlendirme yöntemleri.

\begin{tabular}{|c|l|l|}
\hline Güvenilirlik & \multicolumn{1}{|c|}{ Geçerlilik } \\
\hline Norm-Referans Güvenilirliği & & Kapsam Geçerliliği \\
\hline Formun Tekrarı Yöntemi & & Kriter Geçerliliği \\
\hline Eşdeğer (Paralel) Formlar Yöntemi & & Kestirimsel Geçerlilik \\
\hline İç Tutarlılık Yöntemleri & & Uyum Geçerliliği \\
\hline Yarıya Bölme Yöntemi & & Yapı Geçerliliği \\
\hline Kuder-Richardson Güvenilirlik Katsayıları & Güvenilirlik & Görünüş Geçerliliği \\
\hline Cronbach Alfa Güvenilirlik Katsayısı & & \\
\hline Teta Güvenilirlik Katsayısı & & \\
\hline Omega Güvenilirlik Katsayısı & & \\
\hline Guttman Güvenilirlik Katsayıları & & \\
\hline Kriter-Referans Güvenilirliği-Livingston Formülü & & \\
\hline
\end{tabular}

göre sayı verme ișlemi”, TDK Toplumbilim Terimleri 1975'e göre İngilizce 'measurement' karş1l lığ 1 olarak "Türlü toplumsal olguların özelliklerini uygun ölçü araçları kullanarak sayısal olarak saptamaya yönelik bir bilme süreci”, TDK Yöntembilim Terimleri Sözlüğü 1981'e göre İngilizce 'measure' karşılığı olarak “ölçüye vurulan bir konuda bir ölçme araciyla elde edilen ve ölçme dizgesinin çeşitli birimleriyle dile getirilen değer" olarak tariflenmektedir (13).

Ölçmek ve ölçer ise TDK Güncel Türkçe Sözlük'e göre "en, boy, hacim, süre gibi nicelikleri kendi cinslerinden seçilmiş bir birimle karşılaştırıp kaç birim geldiklerini belirtmek" olarak tariflenmektedir (13).

Ölçme aracının standart olabilmesi için "güvenilirlik" ve "geçerlilik" olarak nitelendirilen iki özelliğinin olması gerekir. Güvenilirlik, bir ölçme aracıyla aynı koşullarda tekrarlanan ölçümlerde elde edilen ölçüm değerlerinin tutarlılığının bir göstergesidir. Geçerlilik ise bir ölçme aracının ölçümü amaçlanan özelliği, herhangi bir başka özellikle karıştırmadan, doğru olarak ölçebilme yeteneğidir $(8,14)$.

Ölçümlerin tutarlılığ1; birbirini izleyen ölçmelerde, ölçüm değerinin grup içindeki sırasının değişmezliği ve birbirini izleyen ölçümlerde ölçme hatalarının düşük olması yani ölçeğin tekrarlanan ölçümlerde aynı örnekten yaklaşık olarak aynı ölçüm değerini elde etmesi ile değerlendirilir. Güvenilirlik sadece ölçme aracına ait bir özellik de değildir ve aracın ürettiği sonuçlarla da ilişkilidir. Elde olunan bilgilerin tutarlı1ık taşıdığına, yani hatadan arınmış olduğuna ve aynı amaçla yapılacak olan ikinci ölçümlerde aynı sonuçların çıkacağına duyulan güvenin karşılığıdır $(8,14,15)$.

Bir ölçme aracının geçerliliği, standart koşullarda elde edilen bir ölçüm değerindeki değişkenliğin ne kadarının, incelenen örneklerin ölçülen özelliği taşıma miktarları arasındaki gerçek farkı yansıttığını gösterir. Ölçülen özelliğe sahip olma bakımından örnekler arasındaki gerçek farklardan oluşan değişkenlik, ölçümlerdeki toplam değişkenliğe oranlanarak hesaplanır. Elde edilen ölçümler hangi amaçla kullanılacaksa ölçümün geçerliliği de o amaca bağl1 olarak değişir. Geçerlilik, kullanılış amacına, uygulanan örnek grubuna, uygulama ve değerleme biçimine de bağlı olarak oluşur $(8,14,15)$.
Tam güvenilir ve geçerli bir ölçme yapmak imkânsız olduğundan, ölçmenin güvenilirliğini ve geçerliliğini arttırmak için en az hata yapmak gereklidir. Herhangi bir ölçüm sürecinde elde edilen değerlerde bir miktar gerçeklik ve bir miktar da ölçüm hatası bulunur $(8,9,14,15)$.

Bir ölçme aracının güvenilirliği, gerçek değerlerin varyansının gözlenen değerlerin varyansına oranlanmasıyla elde olunan ve hatasızlığın ölçüsü olan bir grup istatistiği ile yani "güvenilirlik katsayısı" ile bulunulabilir. Uygulamada gerçek değerlerin bilinmesinin imkânsızlığı nedeniyle güvenilirlik katsayısı farklı durumlara yönelik olarak dolaylı yollardan hesaplanır(Tablo 3) (9).

Birkaç ölçücü veya ölçümü içeren bir güvenilirlik çalışmasında; Ortalama Grup İçi Uyum Katsayısı, farklı ölçücü ya da ölçümlerin değerlerinin ortalamasından oluşan sıralı bir ölçeğin güvenilirliğini gösterir. Bunun aksine olarak, Tek Grup İçi Uyum Katsayısı ise farklı ölçücülerin ya da çeşitli ölçümlerin bulunduğu siralı ölçekte sadece birinin değerinin güvenilirliğini gösterir (15).

Cronbach (16) tarafından bir iç tutarlılık tahmin yöntemi olarak geliştirilen alfa kat sayısı, ölçekte yer alan maddelerin varyanslarının toplamının genel varyansa oranlanması ile hesaplanan ağırlıklı standart bir değişim ortalamasidir.

$\mathrm{Bu}$ çalışmada bu katsayının çap ölçümlerinde özellikle de karotis arterde en düşük değerleri almasına rağmen; 0,8 değerinin üzerinde değerler göstererek (Tablo 1) "iyi" ve "mükemmel" karşılıklarını bulması güvenilirlik için oldukça iyi sonuçlar olduğunu göstermektedir. Ölçülen parametre sayısı arttıkça alfa katsayısının artışı işlem toplamının ölçücüler arasında minimal fark oluşturduğunu göstermektedir. Tek bir ölçümdeki uyum değerleri, her ne kadar karotis arterde en düşük değerlere ulaşsa da ortalama değerler kullanıldığında güvenilirlik oranları göstermektedir.

$\mathrm{Bu}$ çalışmanın bulguları, geçmiş ve gelecekteki çalışmalarda farklı ölçücüler tarafından sağlanan sonuçların güvenilirliğinin ve ölçücüler arasında uyum olacağının istatistikî göstergesidir. 


\section{KAYNAKLAR}

1. Lakatta EG. Arterial and cardiac aging: major shareholders in cardiovascular disease enterprises: Part III: cellular and molecular clues to heart and arterial aging. Circulation 2003; 107:490-497.

2. Wada T, Kodaira K, Fujishiro K, et al. Correlation of ultrasound-measured common carotid artery stiffness with pathological findings. Arterioscler Thromb 1994; 14:479-482.

3. Avolio AP, Chen SG, Wang RP, et al. Effects of aging on changing arterial compliance and left ventricular load in a northern Chinese urban community. Circulation 1983; 68:50-58.

4. Lehmann ED, Gosling RG, Sonksen PH. Arterial wall compliance in diabetes. Diabet Med 1992; 9:114-119.

5. Nicholas WW, O'Rourke MF, McDonald DA. McDonald's blood flow in arteries : theoretic, experimental, and clinical principles. 3rd ed. Philadelphia: Lea \& Febiger, 1990.

6. S, Boutouyrie P, Asmar R, et al. Aortic stiffness is an independent predictor of all-cause and cardiovascular mortality in hypertensive patients. Hypertension 2001; 37:1236-1241.

7. Ercan İ, Kan İ. Ölçeklerde güvenirlik ve geçerlik. Uludağ Üniversitesi Tıp Fakültesi Dergisi 2004; 30:211-216.

8. Carmines EG, Zeller RA. Reliability and validity assessment. Beverly Hills, Calif.: Sage Publications,
1979.

9. Rubin A. Statistics for evidence-based practice and evaluation: Cengage Learning, 2012.

10. Arnett DK, Evans GW, Riley WA. Arterial stiffness: a new cardiovascular risk factor? Am J Epidemiol 1994; 140:669-682.

11. Hodes RJ, Lakatta EG, McNeil CT. Another modifiable risk factor for cardiovascular disease? Some evidence points to arterial stiffness. J Am Geriatr Soc 1995; 43:581-582.

12. Baykara M, Öztürk C, Elbüken F. The relationship between bone mineral density and arterial stiffness in women. Diagn Interv Radiol 2012; 18:441-445.

13. Büyük Türkçe Sözlük - TÜRK DİL KURUMU. Available at: http://www.tdk.gov.tr/index. php?option=com_bts. Accessed May 15, 2015.

14. Mertens DM. Research and evaluation in education and psychology: Integrating diversity with quantitative, qualitative, and mixed methods: Sage Publications, 2014.

15. Streiner DL, Norman GR, Cairney J. Health measurement scales: a practical guide to their development and use: Oxford university press, 2014.

16. Cronbach LJ. Coefficient alpha and the internal structure of tests. Psychometrika 1951; 16:297-334. 